\title{
Robot-assisted versus conventional laparoscopic fundoplication: short-term outcome of a pilot randomized controlled study
}

\author{
H. Wykypiel · J. Bodner $\cdot$ G. Wetscher $\cdot$ \\ T. Schmid
}

Received: 5 November 2007/Accepted: 30 November 2007/Published online: 25 March 2008

(C) Springer Science+Business Media, LLC 2008

We read with great interest the recent Surgical Endoscopy publication entitled "Robot assisted versus conventional laparoscopic fundoplication: short-term outcome of a pilot randomized controlled study". The authors come to the conclusion that-besides shortened operation time-the application of the operation robot does not reveal a further benefit in laparoscopic fundoplication. In 2002 we were able to perform a pilot study on robot-assisted laparoscopic Toupet fundoplication with the DaVinci ${ }^{\circledR}$ surgical system (Intuitive Surgical, Mountain View, Calif., USA) with a 6month follow-up and came to the same conclusion except for an even longer set-up and operating time in our series [1]. Despite demanding experience of the surgeon in order to obtain a good functional outcome the performance of a laparoscopic fundoplication does not require the four main advantages of robot assisted laparoscopic surgery: it is not an operation that cannot be performed laparoscopically without the robot [2]; it does not require microscopic view and movements of the arms; anatomically it is not an operation in a remote or narrow operating field [3, 4]; and in a normal laparoscopic fundoplication no complex manoeuvres such as creation of an intracorporeal anastomosis or complex suturing [5] are needed.

Improved ergonomics for the surgeon and a shorter set-up and operation time as a matter of training (as demonstrated in the above mentioned paper) do not outweigh higher operative costs as long as no further clear advantage is proven.
Laparoscopic redo fundoplications [6] often consist of an even more demanding intraoperative situation where the operation robot could allow for a more precise dissection, avoiding inadvertent lacerations (e.g., lacerations of the vagus nerve), and therefore lead to a better outcome. For training purposes in order to be prepared for such more demanding applications the performance of robot-assisted laparoscopic fundoplications seems justified.

\section{References}

1. Wykypiel H, Wetscher GJ, Klaus A, Schmid T, Gadenstaetter M, Bodner J, Bodner E (2003) Robot-assisted laparoscopic partial posterior fundoplication with the DaVinci system: initial experiences and technical aspects. Langenbecks Arch Surg 387:411-416

2. Marescaux J, Rubino F (2006) Robotic surgery: potentials, barriers and limitations. Eur Surg 37:279-283

3. Wykypiel H, Bonatti H, Hinder RA, Glaser K, Wetscher GJ (2006) The laparoscopic fundoplications: Nissen and partial posterior (Toupet) fundoplication. Eur Surg 38:244-249

4. Meehan JJ, Sandler A (2007) Pediatric robotic surgery: a singleinstitutional review of the first 100 consecutive cases. Surg Endosc 2007 May 24 (Epub ahead of print)

5. Ishikawa N, Sun YS, Nifong LW, Chitwood WR Jr, Oda M, Ohta Y, Watanabe G (2006) Thoracoscopic robot-assisted bronchoplasty. Surg Endosc 20:1782-1783

6. Wykypiel H, Kamolz T, Steiner P, Klingler A, Granderath FA, Pointner R, Wetscher GJ (2005) Austrian experiences with redo antireflux surgery. Surg Endosc 19:1315-1319

H. Wykypiel $(\bowtie) \cdot J$. Bodner · T. Schmid

Department of General and Transplant Surgery,

Medical University, Innsbruck, Austria

e-mail: heinz.wykypiel@uibk.ac.at

G. Wetscher

Department of Surgery, Hospital of Schwaz, Schwaz, Austria 